\title{
Keratinophilic Fungi: a microscopic approach by in vitro hair perforation analysis
}

\author{
R. Sabino*, C. Verissímo*, J. Brandão*, C. Alves*, P. Alves*, H. Parada*, L. Rosado* \\ * Unidade de Micologia, Instituto Nacional de Saúde Dr. Ricardo Jorge, Av. Padre Cruz, 1649-016 \\ Lisboa, Portugal \\ raquel.sabino@insa.min-saude.pt
}

Nowadays, environmental moulds are often being referred as also being the cause of superficial mycosis. Keratinophilic activity is one of the characteristics involved in the infectious process of some fungal species. With these findings some problems appear: 1) Do these species really act on keratinized tissues?; 2) How do these fungi perform their keratinophilic activity?; 3) Should we validate the results as positives in the case of isolating from the lesions only species considered as environmental? To answer to these questions, the in vitro hair perforation test was performed in 60 different species, including dermatophytes and environmental isolates. In vitro perforation capability, believed to be one of the characteristics involved in some fungal infectious processes, was assessed with aid of optic-, fluorescence-, electron scanning- and transmission-microscopy, followed by calculation of keratinophilic activity. According to Ali-Shtayeh et al. [1], each hair degradation factor has a specific weight in a keratinolytic activity intensity index called "IKA", which ranges between 0 and $100 \%$. Changes in the hair structure may occur in the two following different ways [1,2,3]: (a) Superficial Erosion, where there is an even hair degradation from the outside to the inside (b) Radial Penetration where there is a localized degradation of hair surface, often in a pocket-like structure. Different types of hyphce are observed: of narrow diameter called boring hyphce, of larger diameter called wider boring hyphoe) and swollen boring hyphce (with dilated tips). Hyphoe may also produce highly specialized perforation organs.

For this purpose, were performed in vitro hair perforation tests according to [4]. Preparations were incubated at $27 \pm 2^{\circ} \mathrm{C}$ for 5 weeks, under weekly observations. In Optic Microscopy (OM), observations were made using lactophenol blue stain. In Fluorescence Microscopy (FM), sample preparations were achieved by adding $\mathrm{KOH}(10 \%)$. After shaking slightly, 2 drops of Calcofluor White (Difco) were added, and let rest for 2 minutes. FM observations were made using a fluorescence microscope (330-385 nm). For Scanning Electron Microscopy (SEM) samples were dehydrated (hairs were retrieved from culture medium and exposed to air, overnight), and metalized (cathodic pulverization with gold particles). For Transmission Electron Microscopy (TEM), sample preparations were achieved by fixating hairs with gluteraldeide and dehydration in ethanol according to [5].

Following the work of Ali-Shateayeh et al. [1] where an intensity of keratinophylic activity is defined as IKA $((\mathrm{IKA}=$ Fungal growth $(0-5 \%)+$ Sporulation rate $(0-5 \%)+$ Uniform superficial erosion $(0-10 \%)+$ Superficial erosion forming concavities $(0-20 \%)+$ Boring hyphae $(0-10 \%)+$ Wider boring hyphae $(0-20 \%)+$ Swollen boring hyphae $(0-10 \%)+$ Perforating organs $(0-20 \%))$. In case of complete hair degradation, the IKA index sums $100 \%$. Based on these values, four keratinophilic fungi categories were considered, also following the work of Ali-Shateayeh et al.: 'no keratinophilic activity' (IKA ranging between 0 and 9\%); 'weak keratinophilic activity' (IKA ranging between 10 and 39\%); 'medium keratinophilic activity' (IKA ranging between 40 and 59\%) and 'strong keratinophilic activity' (IKA ranging between 60 and 100\%). 
In our mycology lab (period 2001-2006), a high percentage of nail lesions was observed (64\%), followed by skin lesions (29\%) and hair shaft lesions (7\%). Yeasts were isolated from $56 \%$ of all lesions and moulds from $44 \%$, out of which, only $48 \%$ were caused by dermatophytes Trichophyton rubrum (22\%), T. verrucosum (7\%), T. soudanense (7\%), T. mentagrophytes (14\%), Trichophyton sp. (7\%), Microsporum canis (22\%) and Epidermophyton floccosum (21\%). From the remaining $52 \%$ of the lesions other non-dermatophytes moulds were isolated, which are considered as mainly environmental - Alternaria spp. (28\%), Scytalidium spp. (12\%), Penicillium spp. (18\%), Fusarium spp. (6\%), Scopulariopsis brevicaulis (6\%), Chaetomium spp. (6\%), Scedosporium sp. (6\%), Aspergillus spp. (18\%). Sixty different fungal species were tested by in vitro hair perforation tests. Figure 1 and 2 shows examples of superficial erosion, where fungi gradually destroy hairs from outside (the cuticula) from inside (the medulla). In this kind of erosion, 2 different types of superficial erosion could occur: uniform superficial erosion (Figure 1 ( $a, b, c, d)$ ) and localized superficial erosion (Figure 2). In radial penetration (Figure 3), fungal species produce specialized hyphae that penetrate in right angles the hair surface. These hyphae trough all hair components, from cuticula to medulla. The most specialized type of hyphae produce is the perforating organ (Figure 4).

According to the observations made, the IKA index was calculated for all specimens. Based on this index we determined that $35 \%$ of the fungi studied display a strong keratinophilic activity (including the environmental fungi Chrysosporium keratinophilum, Scedosporium apiospermum, Scytalidium dimidiatum, Scopulariopsis brevicaulis), 40\% displayed a medium keratinophilic activity (including the environmental fungi Fusarium moniliforme, Fusarium solani, Fusarium chlamydosporum, Penicillium citrinum, Acremonium strictum), 20\% display week keratinophilic activity and the remaining 5\% show no keratinophilic activity, as indicated in Table 1.

We observed a high proportion of species that had medium or strong keratinophilic activity. Escobar \& Carmona-Fonseca [6] and Gugnani [7] showed that some species considered as environmental saprophytes might, in fact, play a pathogenic role. Our work revealed the same. So, it's expected that these species isolated from keratinized tissues and in presence of clinical symptoms could be considered as the ethiological agent.

In conclusion, all keratinophilic fungi have capacity to invade hair in vitro, in spite of differences on how they succeed. With this work we observed different structures developed by nondermatophytic fungi in order to metabolize keratin. We conclude that some environmental fungi possess a surprisingly high keratinophilic activity.

\section{References}

[1] M. Ali-Shatayeh and R. Jamous, Rev Iberoam Micol - Suplem. Biology of Dermatophytes and other Keratinophilic Fungi 17 (2000) 51-59

[2] V. Marchisio and A. Fusconi, Rev Iberoam Micol - Suplem. Biology of Dermatophytes and other Keratinophilic Fungi 17 (2000) 86-92

[3] V. Marchisio, Medical Mycology 39 (3) (2001) 287-294

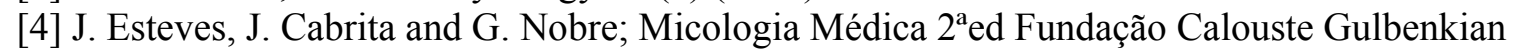
(1990)

[5] V. Marchisio and A. Fusconi, Mycoses 34 (1991) 153-165

[6] M. Escobar and J. Carmona-Fonseca, Rev. Iberoam Micol. 20 (1) (2003) 6-10

[7] H. Gugnani, Rev Iberoam Micol - Suplem. Biology of Dermatophytes and other Keratinophilic Fungi 17 (2000) 109-114 

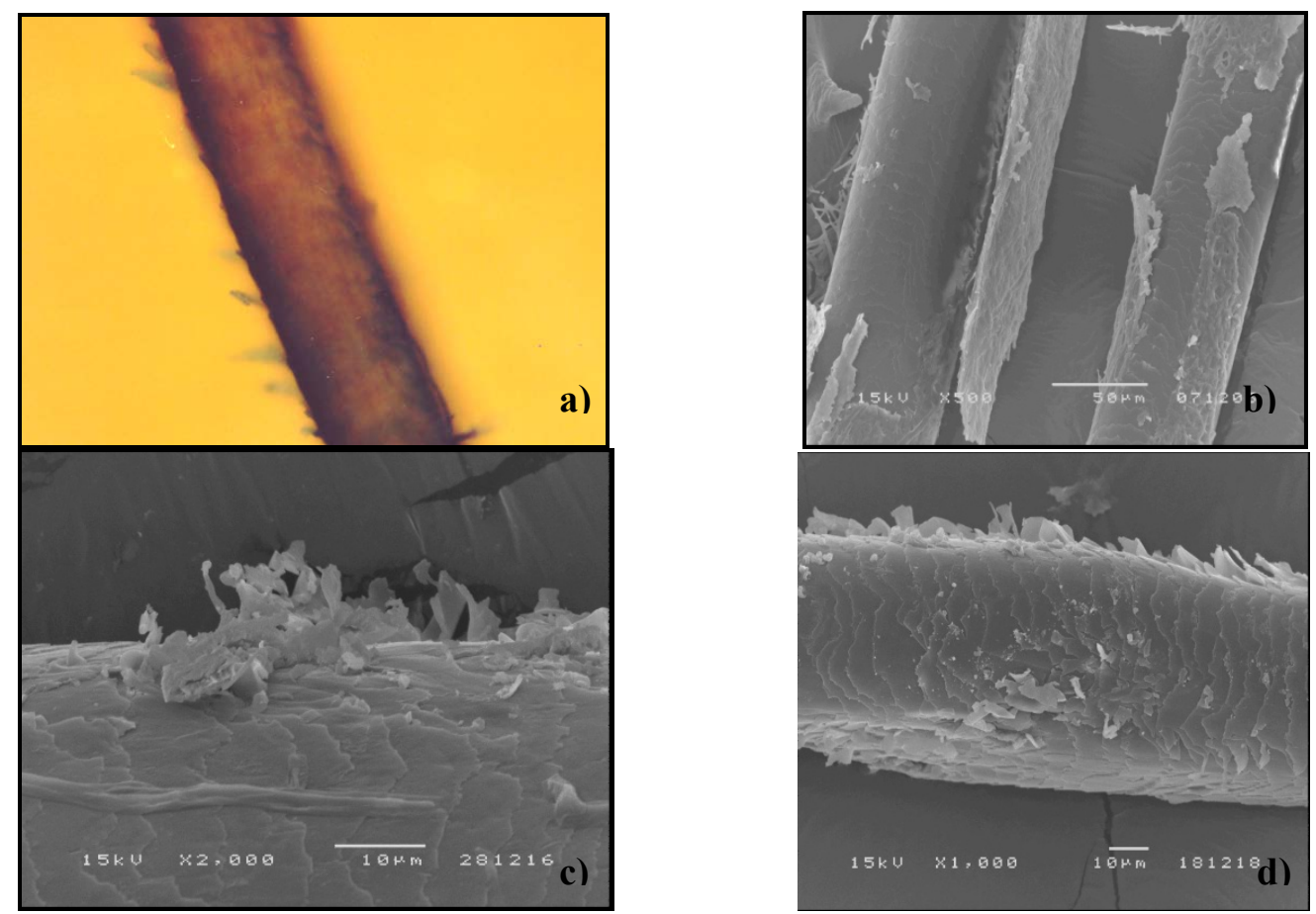

Figure 1. (a) OM: Hair infected with Fusarium solani (x400); (b) SEM: Hair infected with Penicillium citrinum (x500); (c) SEM: Hair infected with Fusarium solani (x2000); (d) SEM: Hair infected with Epicoccum nigricans (x1000)

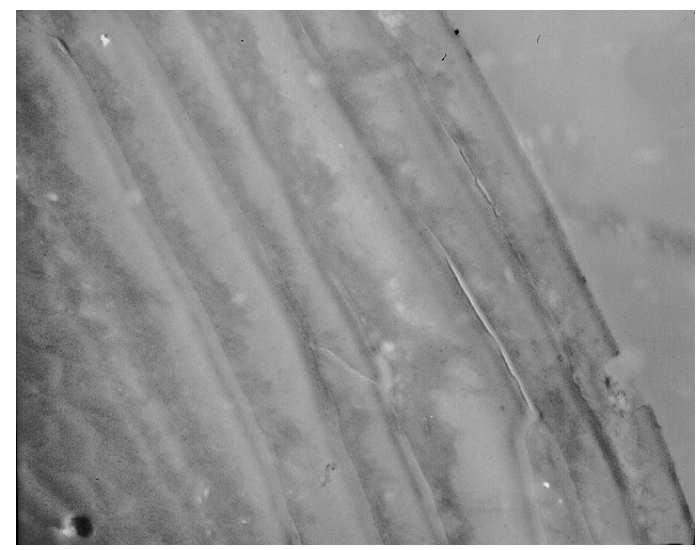

Figure 2. TEM: Hair infected with Fusarium solani (x2000) 

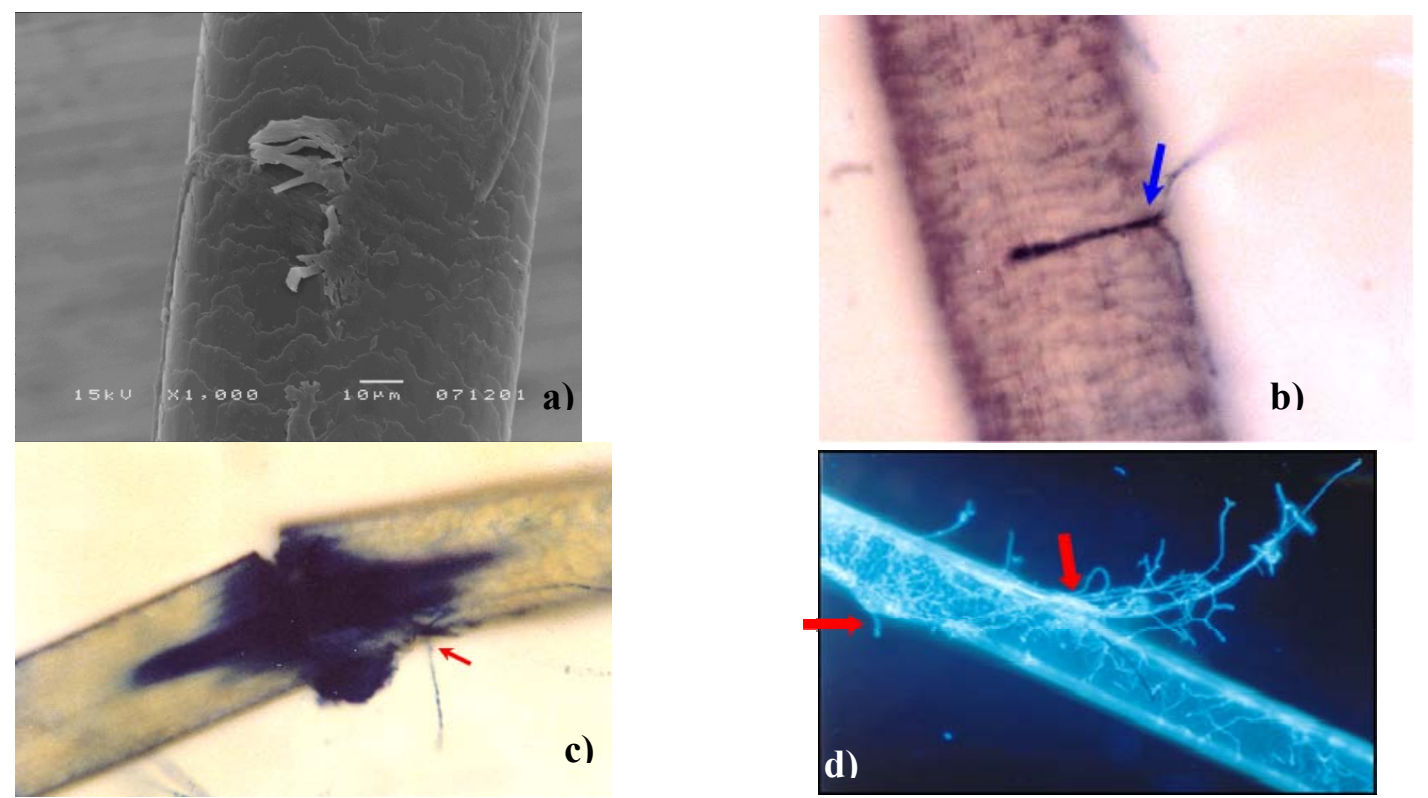

Figure 3. (a) SEM: Hair infected with Penicillium citrinum (x1000); (b) OM: Hair infected with Fusarium solani (x400); (c) OM: Hair infected with Penicillium purpurogenum (x400); (d) FM: Hair infected with Scytalidium dimidiatum (x400)

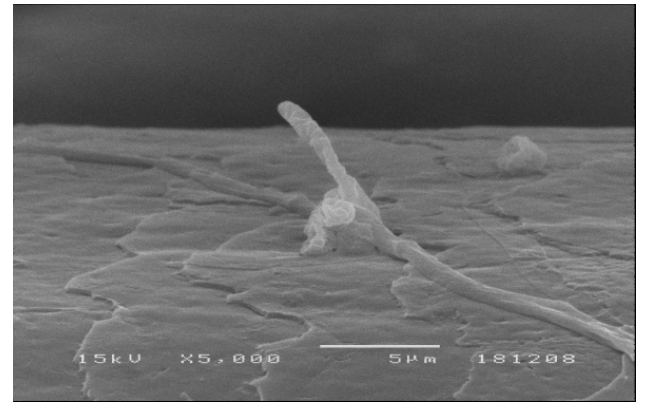

Figure 4. SEM: Hair infected with Penicillium citrinum (x5000)

Table 1- Classification of the studied species in what respect to keratinophilic fungi

\begin{tabular}{|c|c|c|c|c|}
\hline $\begin{array}{l}\text { Total number } \\
\text { of species } \\
\text { studied on } \\
\text { in vitro hair } \\
\text { perfuration test }\end{array}$ & $\begin{array}{l}\text { Number of } \\
\text { species studied } \\
\text { on in vitro hair } \\
\text { perfuration test } \\
\underline{\text { Without }} \\
\frac{\text { keratinophilic }}{\text { activity }}\end{array}$ & $\begin{array}{l}\text { Number of } \\
\text { species studied } \\
\text { on in vitro hair } \\
\text { perfuration test } \\
\text { With weak } \\
\frac{\text { keratinophilic }}{\text { activity }}\end{array}$ & $\begin{array}{l}\text { Number of } \\
\text { species studied } \\
\text { on in vitro hair } \\
\text { perfuration test } \\
\text { With medium } \\
\text { keratinophilic } \\
\text { activity }\end{array}$ & $\begin{array}{l}\text { Number of } \\
\text { species studied } \\
\text { on in vitro hair } \\
\text { perfuration test } \\
\text { With strong } \\
\frac{\text { keratinophilic }}{\text { activity }}\end{array}$ \\
\hline 60 & 3 & 12 & 24 & 21 \\
\hline
\end{tabular}

